\title{
Iron-selective Poly(Vinyl Chloride) Membrane Electrode Based on Norfloxacin as a Neutral Carrier
}

\author{
Amr L. Saber ${ }^{1,2^{*}}$, Ahmed M. Hameed ${ }^{2}$, Ali A. Sayqal ${ }^{2}$ Hussain Alessa ${ }^{2}$, \\ Ahmed Alharbi ${ }^{2}$ \\ ${ }^{1}$ Chemistry Department, Faculty of Science, Zagazig University, 44519- Zagazig, Egypt. \\ ${ }^{2}$ Department of Chemistry, Faculty of Applied Science, Umm Al-Qura University, Makkah, Saudi \\ Arabia. \\ *E-mail: alshefny@yahoo.com
}

doi: $10.20964 / 2018.11 .32$

Received: 5 February 2018 / Accepted: 2 June 2018 / Published: 1 October 2018

In the present study ion-selective PVC membrane sensor for iron ions based on (norfloxacin)1-ethyl-6fluoro-1,4-dihydro-4-oxo-7-(1-piperazinyl)-3-quinoline carboxylic acid (NOR) as adequate ionophor has been prepared and studied. The electrode exhibit a good response for $\mathrm{Fe}^{3+}$ over a linear range from $1.0 \times 10^{-5}$ to $1.0 \times 10^{-1} \mathrm{~mol}^{-1}$ with a slope of $19.58 \pm 0.2$ and $19.27 \pm 0.2 \mathrm{mV}$ per decade and a detection limit of $(5.0 \pm 1.0) \times 10^{-6} \mathrm{~mol} \mathrm{l}^{-1}$ for $o$-nitrophenyl octyl ether (o-NPOE) and dioctylphthalate (DOP) plasticized based membrane sensors, respectively. The investigated membrane electrode revealed good and fast response in a $\mathrm{pH}$ range of 3.0-8.0 for more than 4.0 months without any considerable difference in potentials. The proposed sensor shows comparatively good selectivities with respect to alkali, alkaline earth and some transition and heavy metal ions. It was utilized as an indicator electrode in potentiometric determination of iron ions in some real samples.

Keywords: PVC sensor; Environmental samples; Iron (III) determination; Norfloxacin.

\section{$\underline{\text { FULL TEXT }}$}

(C) 2018 The Authors. Published by ESG (www.electrochemsci.org). This article is an open access article distributed under the terms and conditions of the Creative Commons Attribution license (http://creativecommons.org/licenses/by/4.0/). 